\title{
El dibujo infantil: Trazos, colores e historias que nos hacen reflexionar y aprender
}

\author{
Children's Drawings: Strokes, Colors and Stories that Make Us Reflect and Learn
}

\author{
Amalia Molina-Jiménez' \\ Pan American School \\ Heredia, Costa Rica \\ molina.amalia37@gmail.com
}

Recibido 3 de noviembre de 2013 • Corregido 26 de setiembre de 2014 • Aceptado 31 de octubre de 2014

Resumen. El propósito de este artículo es evidenciar por medio de la investigación acción participativa la evolución del dibujo infantil de cinco niñas y cinco niños en edades entre los cuatro y los cinco años, en cuanto a la construcción de la figura humana, el uso del color y la ubicación de los objetos en el espacio, en un período de seis meses. El dibujo fue el medio de expresión que niños y niñas utilizaron para comunicar de forma visual sus sentimientos, pensamientos, deseos, emociones e intereses, permitiéndole a la docente investigadora construir nuevos aprendizajes. Estos, junto con los de los niños y niñas, crearon una ruptura paradigmática que transformó la labor de la docente de arte, desde la mirada infantil, en la vivencia cotidiana del aula, que le ayudó a descubrir que puede desprenderse de prejuicios y de esa visión adulta que muchas veces limita a los niños y niñas en su ser y en su hacer.

Palabras claves. Arte infantil, transformación, cambio, investigación-acción, docente aprendiz, creatividad, convivencia.

Abstract. The purpose of this participatory action research is to evidence the drawing evolution of five boys and five girls, ages 5 and 6 , regarding the construction of the human body, the use of color, and the location of objects in space over a six-month period. Drawing was the way in which children visually expressed their feelings, thoughts, desires, emotions, and interests. This let the teacherresearcher build new learning, which, together with the one constructed by the children, broke the paradigm and transformed the art teacher's role in the classroom, from the children's perspective. This helped the teacher realize that it is possible to get rid of prejudices and the adult point of view that frequently restricts children in what they are and what they do.

Keywords.Children's art, transformation, change, action research, apprentice teacher, creativity, coexistence.

\footnotetext{
1 Magister en Pedagogía con Énfasis en Desarrollo y Atención Integral de la Primera Infancia. Licenciada en Docencia con énfasis en Arte y Comunicación Visual. Bachiller en Arte y Comunicación Visual con Énfasis en Dibujo. Experiencia docente en instituciones educativas privadas y públicas costarricenses. Labora como docente de artes plásticas en niveles de preescolar y primer ciclo de la institución Pan-American School, San Antonio de BelénHeredia. Actualmente está finalizando el grado de Maestría en Pedagogía con énfasis en desarrollo y atención integral de la primera infancia en la Universidad Nacional de Costa Rica.
} 
doi: http://dx.doi.org/10.15359/ree.19-1.10

URL: http://www.una.ac.cr/educare

CORREO: educare@una.cr

\section{Introducción}

La persona docente se vuelve investigadora de su propia práctica, porque desde su quehacer logra discernir las necesidades y se plantea preguntas sobre su labor: ¿cómo mejorar?, ¿qué debe cambiar?, y ¿de qué manera los niños y niñas a su cargo son la mejor guía para llegar de forma conjunta a las respuestas y soluciones? Este artículo pretende mostrar hallazgos que surgieron en la experiencia con cinco niños y cinco niñas del nivel de prekinder ${ }^{2}$ de la institución Pan-American School, con base en un trabajo apoyado en la modalidad de investigación-acción, realizado en el marco de la Maestría en Pedagogía con Énfasis en Desarrollo y Atención Integral de la Primera Infancia.

Como docente de artes plásticas, sé que esta es una profesión maravillosa que permite crear, cambiar y disfrutar, compartir experiencias y aprender conjuntamente con los niños y las niñas. Se vuelve aún más maravillosa, si las actividades artísticas son un complemento de juego y arte; porque se descubre que el movimiento, la libertad, las formas y los colores son parte de un aprendizaje y un lenguaje. Como menciona Vecchi (2013): "cuando hablamos de lenguajes nos referimos a las distintas maneras en que los niños (seres humanos) representan, comunican y expresan su pensamiento por diferentes medios" (p. 63) que se construyen en las vivencias cotidianas y en las experiencias compartidas. El goce está en dejar ser y hacer al niño y la niña, con total libertad, descubrir la magia que tiene el color y cómo interpretan sus dibujos por medio de sus narraciones.

En la convivencia diaria con los niños y niñas, en la labor educativa como docente de arte surgen aspectos que solo en la experiencia con ellos y ellas se logran vislumbrar y descifrar, pues sus dibujos son únicos y con características muy singulares. Una experiencia desde la práctica que nos hace reflexionar sobre lo que se ha venido haciendo en la enseñanza de las artes plásticas en preescolar y nos lleva a comprender que, además de ser docentes, somos adultos y, como tales, tenemos ideas preconcebidas que nos hacen juzgar a los niños y niñas desde una visión adultocentrista, creyendo que enseñar es solo transmitir conocimientos (Freire, 2006). Olvidamos que los niños y niñas poseen amplios saberes que muchas veces desconocemos porque no les hemos dado la oportunidad de demostrar sus capacidades y habilidades.

En el sistema educativo público de nuestro país, los niños en edades preescolares no cuentan con un profesional en artes visuales, sino que son las maestras de grupo quienes se encargan de brindarles espacios para crear, expresar y experimentar. En tales casos, por falta de conocimientos artísticos, se convierten en espacios para construir manualidades, en donde, por lo general, cada uno de los niños repite un patrón de un diseño. En las manualidades creadas

\footnotetext{
${ }^{2}$ Nombre con el que la institución denomina al grupo de niños y niñas en edades entre los cuatro y cinco años.
} 
por los grupos infantiles es común observar pocas diferencias entre lo que hace uno y lo que hizo otro; mientras que si el niño crea sus propias obras (pintando, dibujando, modelando, etc.) puede expresar, a través de estas, sus pensamientos, lo que siente, lo que conoce de todo aquello que lo rodea; puede comunicar sus experiencias y anécdotas, de manera que cada obra creada es un reflejo de su personalidad, de sus necesidades e intereses (Acaso, 2009).

Vemos, entonces, que las experiencias artísticas brindan a los niños y las niñas las posibilidades de comunicarse desde un lenguaje visual, en el cual comunican todo aquello que conocen y la forma en que ellos y ellas perciben su realidad. Crear es para los niños y las niñas algo que emerge de manera natural y con mucha facilidad. Si comprendemos todo lo que su arte conlleva, podremos cambiar nuestra mirada adulta y más que juzgar sus obras, interpretar cada trazo, color y forma; ver en sus dibujos lo que es importante para ellos y ellas. La comprensión no es solo por medio de la observación que podemos hacer de los dibujos infantiles, sino de la escucha como un medio para llegar a conocer lo que existe más allá del pensamiento de niños y niñas (Molina-Jiménez, 2013).

La experiencia de las artes plásticas en edades preescolares se vuelve para el niño y la niña un momento de disfrute en donde puede crear y comunicar por medio de sus trazos. Pero no solo ellos y ellas disfrutan, como docente de artes plásticas también disfruto de todo lo que hacen, son los grandes maestros que nos muestran y guían cuál es el mejor de los caminos a seguir. Es entender un mundo en el cual nuestra imaginación de adultos y adultas es un poco limitada, pero a su lado podemos ser niños y niñas de nuevo.

\section{Entre chanchos, toboganes de agua y casas de sustos}

¡Uuuuhh, qué miedo! Vean qué miedo, arañas... es la casa de sustos. ¡Buuahh, buuahh... buuahh! Vean qué miedo, vean que cuerpo tan miedoso. (Niña de 5 años y 3 meses, 2013)

¿Esta frase le suena extraña? Si usted es una persona adulta, es muy posible que lo primero que va a pensar es: ¿y esto qué es? ¿Pero qué pasa si nuestra mente cambia por un momento ese pensamiento adultocentrista, por uno que deja volar la imaginación como lo harían los niños y niñas en edades preescolares? Y más que pensar que es una frase sin sentido, es conocer la manera en que los niños y niñas en edades entre los cuatro y cinco años interpretan y conciben sus dibujos.

Así, tal vez podríamos ver más allá, sentirnos capaces de descubrir y sorprendernos como ellos y ellas lo hacen, inspirados para transformar nuestra realidad volviéndola fascinante, mirando en los pequeños detalles grandezas de la vida. Podríamos crear con libertad, disfrutar de lo que se hace y compartirlo de manera conjunta en lo cotidiano. Fuimos niños y niñas en algún momento, así que dentro de nosotros existe esa creatividad e imaginación: ¿Qué tan escondidas están? 
doi: http://dx.doi.org/10.15359/ree.19-1.10

URL: http://www.una.ac.cr/educare

CORREO: educare@una.cr

Cuando trabajamos de manera directa con los niños y niñas como participantes de una investigación-acción y nos enfocamos en sus necesidades, vemos que existen historias y anécdotas en las que descubrimos un mundo que para ellos y ellas es nuevo, todas las experiencias vividas las comunican de manera corporal, oral o gráfica. Antes que la palabra empiece a construirse, emerge el cuerpo con toda su fuerza, aparecen las formas y los colores: es el mundo de la creación artística cargado de símbolos. Son esos garabatos y trazos que solemos creer sin significado, "simples rayas", cuando en realidad son una forma de comunicar de manera no verbal las vivencias y conocimientos que niñas y niños adquieren en la relación con su contexto y las experiencias en su entorno. ¡Cuánto podemos aprender de los niños y niñas viendo esas rayas! Simplemente es escuchar lo que como autores de su obra nos quieren decir, no es solo ver, es saber observar detenidamente y entender que es su manera de transformar la realidad, es aprender qué conocen y qué piensan a esas edades, es entender el proceso de creación para lograr realizar las figuras. Poder dibujar es para ellos y ellas todo un reto, porque es plasmar con trazos pensamientos a veces complejos con los que experimentan sus emociones.

Quizás en algún momento un niño o niña nos ha preguntado: “Adivina qué dibujé?". Observamos y nos dejamos llevar por la semejanza con la realidad limitando la imaginación, pensando "se parece a...". Entonces, vemos que ya el niño o niña se sorprende, nos corrige y se extraña de que no miremos lo que él o ella miran. Porque el dibujo dice para él o ella siempre más de sí y de su realidad (Sarlé y Berdichevsky, 2010).

Una manera de evitar este desconcierto mutuo es preguntarles qué significa su creación: ¿Quién más que ellos y ellas nos puede aclarar, desde su singularidad, el significado de sus garabatos y formas? Explicarnos, haciendo uso de una narración impregnada del entusiasmo, imaginación y gesticulaciones, como es característico de los niños y niñas en edad preescolar, al referirse a sus dibujos y a todo aquello que realizan.

Se trata de no detener sus anhelos e ilusiones, como le sucede al Principito cuando nos dice "Las personas mayores me aconsejaron abandonar el dibujo ... Y fue así como abandoné, a la edad temprana de seis años una magnífica carrera de pintor" (De SaintExupéry, 2010, p. 13). Frente a las historias de un niño o una niña hablemos menos y escuchemos más, seamos asertivos y no encasillemos con juicios previos los dibujos infantiles, que siempre estarán llenos de anécdotas, que se vuelven vivientes y con múltiples significados.

Como personas adultas debemos reconocer que siempre hay que aprender, solamente necesitamos creer en que no solo la palabra encierra sentidos. En la niñez también los dibujos son lenguaje, una ventana a la subjetividad del artista y su contexto. Conocer sus dibujos es de alguna manera reconocer su mundo, uno que refleja todo aquello que viven y sienten, 
en donde repiten patrones de una sociedad adulta porque la imagen que tenemos de los niños y niñas no viene a ser otra cosa más que la imagen que tenemos de nosotros mismos (Hoyuelos, 2004).

Estas y otras reflexiones son el resultado de un proceso de investigación acción desarrollado con diez estudiantes entre los cuatro y cinco años (cinco niños y cinco niñas), durante la lección de arte a lo largo de seis meses, quienes a través de sus dibujos me hicieron descubrir y reflexionar acerca de las cualidades que les caracterizan en sus cortas edades, de cómo se empoderan de su accionar, de cómo perciben, reconstruyen y transforman su entorno; de cómo construyen percepciones diversas y con ellas diferentes aprendizajes (Dobles, Zúñiga y García, 2010).

Como docente investigadora, confirmo que las artes plásticas en preescolar abren la puerta a una experiencia maravillosa desde todas las dimensiones: disfrute, diversión, aprendizaje, convivencia, creación, transformación. En la experiencia con ellos y ellas mientras creaban, pude cambiar mi mirada de adulta, comprender, acercarme, conocer sus intereses desde sus percepciones infantiles.

\section{¿Y por qué chanchos?}

El lobo, el chanchito, el otro chanchito y el chanchito más flaco. (Niño de 4 años y 7 meses, 2013)

¿Y por qué no?, con los niños el tema no importa, ellos crean sus dibujos sin temor a cometer equivocaciones, porque el acto creativo se vuelve un disfrute y un goce que se entremezcla con juego y movimiento. Descubren por sí que con trazos crean formas y con estas formas implican historias que se vuelven siempre fascinantes. Es la manera que conocen para expresarse y representar todos aquellos acontecimientos importantes en su vida (Palacios, Cubero, Luque y Mora-Merchán, 2009).

Como docente de arte creía tener las respuestas y las soluciones, les proponía los temas a dibujar, pensando en aquellos que identificaba como los más cercanos a sus intereses y prioridades desde mi conocimiento y percepción, como "experta" en arte. Durante las siete sesiones de trabajo con los niños y niñas en el proceso que conllevó la investigación-acción pude escucharlos detenidamente contar todo lo que representaban sus dibujos, con sus propias palabras narraban y expresaban lo que para ellos y ellas era importante. Lo que me hizo reflexionar y aprender que, antes de la investigación, mi actitud como docente de arte evidenciaba a una persona adulta que quería conducir las creaciones de los niños y niñas hacia resultados predeterminados, limitándoles y restringiendo las posibilidades de decisión, de elección. 
doi: http://dx.doi.org/10.15359/ree.19-1.10

URL: http://www.una.ac.cr/educare

CORREO: educare@una.cr

El tema que los niños y niñas quieren expresar en sus creaciones tendrá siempre una relación con los conocimientos previos, vivencias, desarrollo y aprendizaje construidos en la vida: en el hacer, pensar y sentir. Esta experiencia investigativa me hizo comprender que la decisión de lo que deben dibujar no es nuestra, son ellos y ellas quienes crearán sus dibujos para que el aprendizaje artístico sea pleno, disfrutado con todos los sentidos, de manera que sus producciones provoquen felicidad en esta niñez creadora (Marín, 2003a). Fue con la recopilación de cada una de sus obras, con las narraciones de los significados de los dibujos, en mi rol como sujeto participante y a la vez docente investigadora, que pude ir conociendo de manera más cercana los intereses de los diez participantes y lo que para ellos y ellas era realmente importante representar.

Como personas adultas debemos comprender el proceso gráfico que de manera natural se va desarrollando en los niños y las niñas. A partir de esa comprensión, es posible que los dibujos que ellos y ellas realizan no se clasifiquen en bonitos o feos, buenos o malos, claros o confusos. Esta percepción estética limitada conlleva un trasfondo que está en relación directa con nuestras experiencias pasadas, somos nosotros mismos los que discriminamos creyendo hacer análisis de las composiciones de un dibujo realizado por un niño o una niña, valorando con ciertos elementos artísticos las obras infantiles nuevamente desde la percepción adultocentrista (Hoyuelos, 2004).

El niñoy la niña crean sus obras y en estas realizan composiciones de color asombrosas por el solo placer de explorar. La persona adulta juzga desde sus conocimientos, su realidad, su función muchas veces profesional o técnica mal interpretada. Si nos detenemos a observar, veremos que su comprensión estética puede desarrollarse desde otra mirada, la mirada de la singularidad, el respeto, la sensibilidad creadora. Frente a ellas cada dibujo es una obra de arte que requiere ser compartida, alentada y reconocida. Nos transformamos, entonces, en incentivadores de actos creativos, conscientes de nuestro rol como acompañantes respetuosos. Desde ese lugar, es posible identificar los dibujos como representaciones de vivencias, conocimientos, momentos, gustos, acciones significativas de experiencias desde la integralidad del ser en la familia, con los animales y los objetos, en la vida (Molina-Jiménez, 2013). Un ejemplo de ello es la figura 1, dibujo, en donde el niño creador de su obra se basa en experiencias anteriores que fueron significativas para él, contando una historia no solo desde el lenguaje verbal. Su conocimiento sobre un tema le permite darle vida a las formas representadas con trazos y colores, cada detalle es importante y tiene algo que decir. 


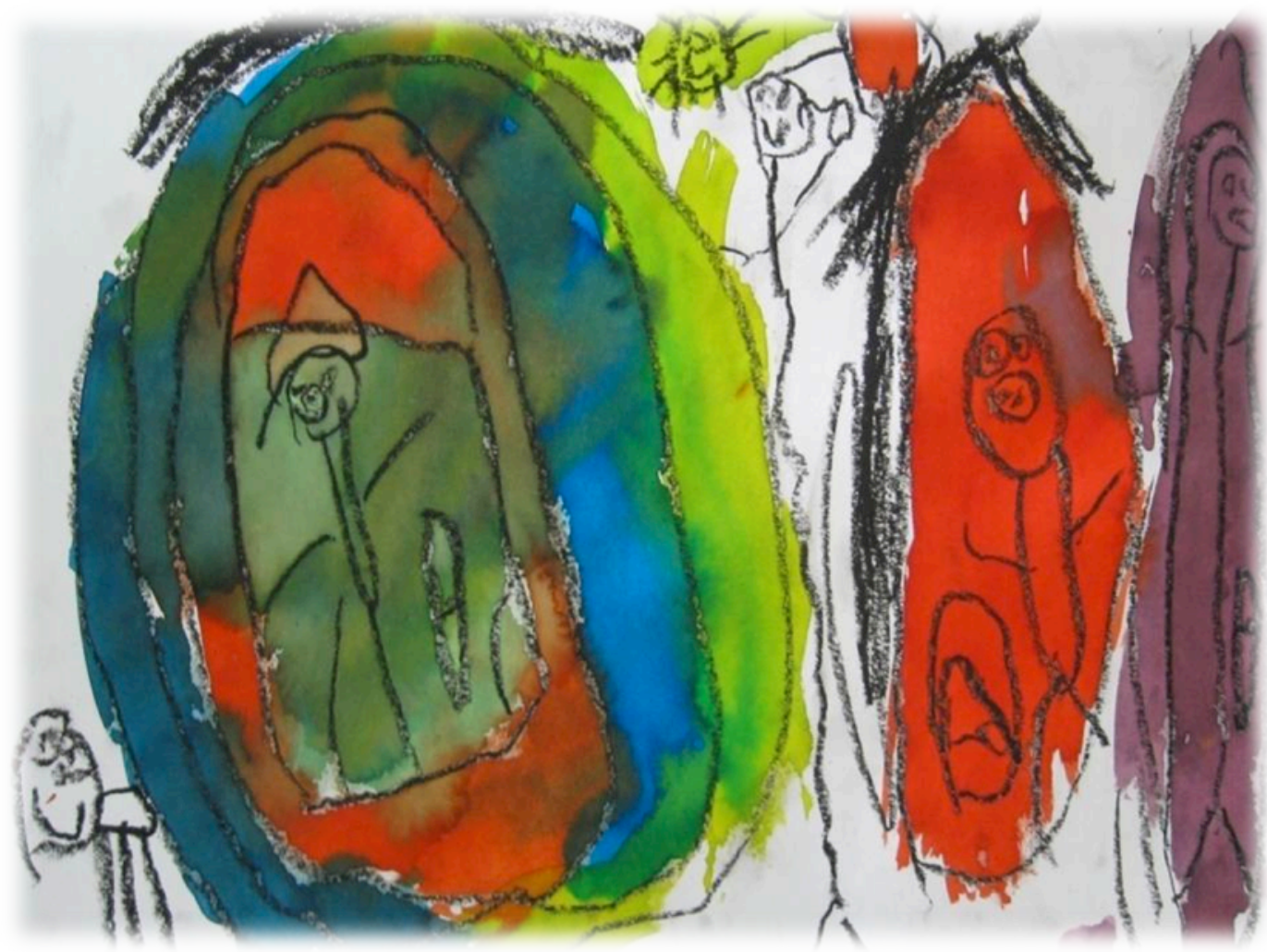

Figura 1. Los tres cerditos ${ }^{3}$.

Voy hacer unos chanchitos. Están paseando; esta es la flauta del chanchito, esta es la chimenea del chanchito; estoy haciendo el lobo feroz. (Niño de 4 años y 7 meses)

En los dibujos que realizaron los niños y las niñas se pudo observar cómo sus garabatos y trazos cambiaban paulatinamente, dando paso a nuevas formas y creaciones. Cada niño y niña era diferente, de igual manera lo fueron sus dibujos, estos respondían a sus características, son un reflejo de sus destrezas, habilidades y conocimientos. Las diez obras recopiladas de cada uno de los niños y niñas permitió poder observar y reflexionar sobre la singularidad del proceso creador en cada participante, las diferencias y similitudes existentes, las influencias que ejercían sus pares en la elaboración de sus dibujos y cómo cada uno de ellos y ellas compartían su entusiasmo por crear, experimentar y comunicar por medio del arte.

${ }_{3}^{3}$ Esta figura por ser propiedad de persona menor de edad, su uso en este artículo es autorizado por su padre. El documento con la autorización se encuentra en los archivos de la Revista Electrónica Educare. 
doi: http://dx.doi.org/10.15359/ree.19-1.10

URL: http://www.una.ac.cr/educare

CORREO: educare@una.cr

No podemos pensar que existen en las obras infantiles dibujos mejores que otros, todos representan sus experiencias y realidades. Constituyen mezclas de lenguajes intensificados con colores, formas, tamaños, texturas e imaginación. En edades preescolares, los niños y niñas comunican todo lo que conocen haciendo uso de formas gráficas, según su etapa de desarrollo ellos y ellas irán agregando cada vez más detalles a sus obras, las formas y elementos representados serán cada vez más reconocibles a la mirada del adulto (Marín, 2003b).

El arte de ver más allá de los trazos radica en cambiar nuestra manera de pensar, reconocer en la producción artística la riqueza de un proceso de construcción de nuevos aprendizajes compartidos es darles la oportunidad de poder ser escuchados uno a uno desde su individualidad. Al prestarles más atención, podemos descubrir todo lo que hay detrás de sus dibujos desde su percepción y realidad: solo al escucharlos podemos darnos cuenta de qué manera ellos y ellas conciben y representan sus experiencias de vida (Sarlé y Berdichevsky, 2010).

\section{Toboganes de agua: el arte también fluye}

Sí, es de agua... es algo resbaloso que uno se pone y esto hace que uno se uuupp y se tira. (Niño de 4 años y 9 meses)

La curiosidad, la creatividad, esas ganas de conocer y de descubrir fluye en los niños y niñas en edades tempranas. Los componentes lúdicos y creativos se conjugan siendo fundamentales en su aprendizaje y desarrollo (Sarlé y Berdichevsky, 2010). El arte y el juego se convierten en instrumentos que permiten a los niños y niñas forjar y construir nuevos conocimientos desde las propias vivencias; ambos les brindan a ellos y ellas múltiples posibilidades de explorar, haciendo uso de los materiales, experimentando con los movimientos de su cuerpo, descubriendo sensaciones y emociones, conociendo por sí mismos ese mundo maravilloso que transforman en formas, gestos e interacciones con otros niños y niñas en edades similares. Como menciona Malaguzzi (citado por Hoyuelos, 2004): "un niño todo aventura: un explorador incansable de las 'praderas' de la mente y la fantasía" (p. 59).

Los niños y niñas disfrutaban el proceso de creación, independientemente de cuál era el material artístico que se les brindaba, comunicaban y expresaban lo que conocían. En mi interacción con ellos y ellas desde la práctica investigativa, descubrí como docente la facilidad y capacidad que poseen de transformar su realidad expresándola con dibujos y palabras, creando su propio sistema de símbolos con los que se comunicaban en un mundo de adultos, donde cualquier objeto podía convertirse en otro, cualquier objeto servía para crear y representar (Marín, 2003b).

La experiencia que obtuve al compartir, crear y experimentar al lado de los niños y niñas desde la enseñanza de las artes plásticas fue un acontecimiento que transformó cada lección, 
convirtiéndola siempre en algo diferente, donde como docente de arte sabía que la flexibilidad era un requisito en el día a día con ellos y ellas. Más que querer enseñarles, descubrí que se trata del gusto de aprender juntos. Se trataba de la convivencia en la cual realmente nos transformamos (Avery, 1991).

Como docentes nuestro rol es ser acompañantes y mediadores del proceso de aprendizaje de los niños y las niñas, la prioridad es hacer que ellos y ellas se sientan partícipes y plenos.

\section{¡Buuahh, buuahh...buuahh! ...¡Sí, así te asustan!}

Es que cuando entré a una casita vi una araña, a una señora sin cara; ... un caballo sin pies y una araña. Y acá había muchas cosas de terror. (Niña de 5 años y 3 meses)

La investigación partió en un principio de una pregunta y unos propósitos por lograr, pero paralelo a estos fueron surgiendo aspectos inesperados que me enseñaron que es de la mano de los niños y niñas como se construye el camino del aprender juntos. Esos aspectos iban apareciendo en el camino y creaban temor, provocando en mí ciertos miedos.

Claro que nos da miedo... miedo de descubrir que somos incapaces de comprender a los más pequeños; de no tener el tiempo para escuchar todo lo que nos tienen que contar y enseñar; miedo de ver que no le damos valor a lo que ellos y ellas consideran como valioso. De descubrir que sus intereses son muy diferentes a los nuestros, de reconocer sus capacidades. Los niños y niñas nos retan a romper las prácticas rutinarias, buscando temas o técnicas de aprendizaje desafiantes, que les permitan desarrollar y potenciar su creatividad. Son ellos y ellas quienes muestran el camino a seguir para cambiar, en búsqueda de los momentos placenteros, de disfrute y libertad (Krishnamurti, 1972).

Estos miedos surgieron con fuerza al iniciar el proceso de investigación; pero se desvanecieron progresivamente cuando acompañábamos el hacer con reflexión. Y pudimos ver con más claridad que juntos docente, niños y niñas participantes compartíamos una misma realidad. Esto permitió que se fomentara una mayor comunicación entre nosotros, generándose nuevas ideas, donde se retomaron acciones más dirigidas hacia el cambio y la transformación de esa realidad compartida. Los miedos se fueron apaciguando porque cada vez me iba dando cuenta de que la investigación-acción desempeñaba una función formativa, que ofrecía esa oportunidad de entender el contexto desde una visión más crítica y trabajar en esa realidad. Una realidad que se veía reflejada en cada una de sus obras, que unidas a sus narraciones me permitía entrar en un mundo que mezclaba realidad y fantasía, que interpretan con gran creatividad. Como sucede en el siguiente dibujo realizado por uno de los niños participantes, donde él va describiendo con su narrativa una experiencia vivida en algún momento y que logra representar 
doi: http://dx.doi.org/10.15359/ree.19-1.10

URL: http://www.una.ac.cr/educare

CORREO: educare@una.cr

de manera gráfica. Los detalles de la descripción son minuciosos y solo al leerla podemos entender lo que para él representan cada uno de sus trazos con tanto movimiento y dinamismo.

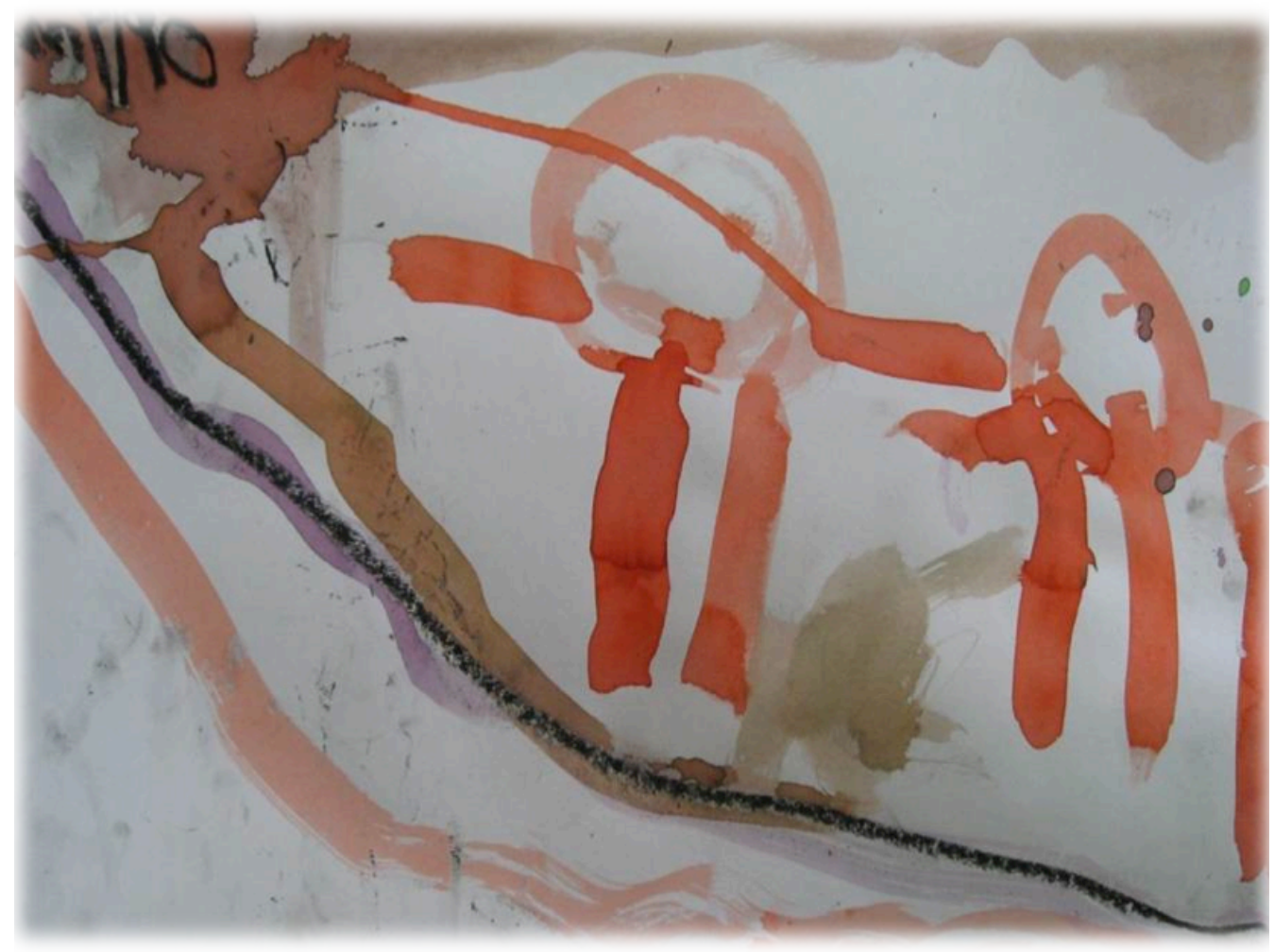

Figura 2. El tobogán de agua4 .

Un tobogán, vea aquí me tiré y estoy aquí; luego voy a hacer más...Sí, es de agua. Teacher, teacher...estas son las gradas y este es el tobogán, estas no son gradas (señala las partes del dibujo que va describiendo), no hay nada, es algo resbaloso que uno se pone y esto hace que uno se uuupp y se tira. Esta es la vesolidad ${ }^{5}$. (Niño de 4 años y 9 meses)

\footnotetext{
${ }^{4}$ Esta figura por ser propiedad de persona menor de edad, su uso en este artículo es autorizado por su madre. El documento con la autorización se encuentra en los archivos de la Revista Electrónica Educare.
}

${ }^{5}$ Se refería a la palabra velocidad. 
Es a la luz de la experiencia vivida que evidencio lo aprendido con los niños y niñas participantes, cómo influyeron en mí y de qué manera esa vivencia compartida me ayuda a remirar mi labor docente desde otra perspectiva, que he de reconocer me satisface y me empuja a comprometerme más en mi profesión de docente de artes plásticas en preescolar.

¡Buuaaahh...! El primero de los sustos fue reconocer que los diez niños y niñas con quienes compartí la experiencia investigativa, en su hacer, motivaron las preguntas acerca de mi quehacer en el contexto del aula. Asumir a niños y niñas como participantes suponía aceptar sus aportes, remirar lo que hago, enfrentar mis desaciertos. Descubrí que los niños y niñas son los acompañantes idóneos, porque nos enseñan a ver la vida de otra manera, a apreciar en cada detalle la belleza de las cosas pequeñas que nos rodean.

Los niños y niñas participantes se convirtieron en la razón de ser del proceso de la investigación, siempre con algo que aportar y compartir. Con ellos y ellas me fui dando cuenta que había cosas nuevas, que surgían caminos no planeados. Únicamente de esta manera evolucionaba y surgía, a su vez, una ruptura paradigmática en mi pensamiento, aunque al principio no era consciente que eso estaba sucediendo. Como indica Freire (2006), se trataba de ser un educador aventurero al igual que los niños y las niñas; de estar dispuesto a aceptar los cambios que aparecían en ese caminar, en un ambiente de respeto mutuo en donde estaría por encima de todo la dignidad de cada uno de los niños y las niñas, un espacio en donde se motivaría y estimularía el entusiasmo, la curiosidad, las ganas de experimentar y descubrir. Las interrogantes serían parte de ese aprender de forma conjunta en donde docente y participantes pudieran más que buscar respuestas, motivar nuevas interrogantes, porque aprender no es el mero acto de transferir conocimientos sino más bien, construirlos y compartirlos en un espacio de calidez, esperanza y alegría.

¡Buuaaahh...!¡Buuaaahh...! Cada aprendizaje viene de la mano del cambio. En mi caso, ello sucedió al descubrir que en mi rol como docente también podía ser investigadora, esto me hizo estar dispuesta a ver mi quehacer desde otra mirada. Una, que causa temor e incertidumbre, una mirada crítica articulada con la de los niños y las niñas. Supuso abandonar el lugar de expertos, de poseedores del saber para alcanzar, como señala Morin (1999), el saber necesario para comprender que las relaciones mutuas nos permiten entender y aprehender de esas influencias recíprocas; nos hacen descubrir que no somos seres fragmentados ni individuales porque formamos parte de un todo y de esta manera crecemos con todos los sentidos y vemos en lo inesperado algo sorprendente, estamos anclados a nuestros propios saberes y teorías con las que nos hemos conducido por diferentes caminos. Por eso, al enfrentarnos al cambio o algo nuevo, nos es difícil romper con esas estructuras paradigmáticas que nos mantienen en un estado de confort, que nos enceguecen y en ocasiones no nos dejan abordar y entender esos nuevos cambios. Es ponernos al descubierto ante nuestras propias ideas, pensamientos y conocimientos para revisar, de forma profunda, y llegar a comprender que el cambio es inherente al ser humano; que la angustia y la incertidumbre son parte de esa transformación constante; que nos hace sentirnos vivos; que nos hace reflexionar y entender 
doi: http://dx.doi.org/10.15359/ree.19-1.10

URL: http://www.una.ac.cr/educare

CORREO: educare@una.cr

que estamos en este mundo por una razón y un propósito. ¿Cuál? No lo sabemos, se comprende en el hacer, en el caminar y en el compartir.

No niego que existió el temor de mirarme y remirarme. Fue en las grabaciones de las siete sesiones con los niños y niñas participantes, y su posterior sistematización, cuando estas me hicieron reconocerme como simple aprendiz y sentir cómo se derrumbaba mi autoimagen de docente experta en arte que creía ser, que no lo sabía todo y que estaba aprendiendo de aquellos a quien creía debía enseñar. Porque nunca antes me había escuchado a mí misma en mi rol como docente de artes plásticas desde otra mirada, pero ahora el instrumento que había utilizado para la recopilación de datos me estaba brindando esa oportunidad. La investigación-acción nos hace descubrirnos y transformarnos, escuchar y escucharnos, vernos de alguna manera reflejados en el otro (Mata, 2008).

Este fue un proceso que se convirtió en todo un reto y una verdadera aventura, que me permitió reflexionar acerca de lo que hago en mi contexto educativo, ser crítica para ser capaz de transformar la manera de educar desde las experiencias y vivencias compartidas con los niños y niñas participantes. Me permitió ver más allá y lo más importante de todo, aprender de los demás.

Con esta modalidad investigativa vivencié un proceso de construcción y transformación; acepté que no se trata de seguir pasos, sino de crearlos en respuesta a la realidad. Ese es el caminar necesario, que incluye devolverse varias veces y empezar de nuevo, mirar y repensar lo recorrido; darnos cuenta de que hay más por aprender, por cambiar, por construir. Es esa construcción de conocimientos de manera conjunta con los niños y niñas logré vislumbrar que en la convivencia e interacción con ellos y ellas está la vida y la belleza que emergen con una ética y estética diversas, inspiradas en un proceso de creación, de libertad, de ser nosotros mismos.

¡Buuahh, buuahh...buuahh! Uno de los sustos más grandes que recibí en esta aventura con los niños y niñas participantes fue verme a mí misma como una docente de artes plásticas con debilidades y flaquezas, con errores, incoherente con ese discurso de crear con libertad. Conocerme a mí misma y darme cuenta qué debo cambiar:

- Reconocer en los demás individuos las enseñanzas que me brindan acerca de mi labor.

- Saber que las necesidades de cada niño y niña son diferentes y se deben respetar porque no hay momentos para crear, sino libertad para hacerlo.

- Brindar oportunidades de expresión gráfica que incentiven el entusiasmo por crear, inventar y descubrir un mundo que es nuevo cada día.

Los dibujos realizados por los niños y niñas me permitieron reflexionar sobre mi manera de construir educación, de interactuar, de humanizar el entorno educativo, de aportar nuevos conocimientos; de reconocer la búsqueda de momentos de calidad en los cuales tengamos tiempo para compartir, expresary, lo más importante, ser escuchados yescuchadas (Avery, 1991). Porque en la 
escucha aprendemos y conocemos cómo las experiencias vividas de cada uno de los niños y niñas van transformando su realidad, vemos cómo van adquiriendo nuevos conocimientos desde su contexto, cómo el dibujo se vuelve un instrumento para poder comunicar, expresar historias y anécdotas como las que se muestran en el siguiente dibujo, realizado por una de las niñas participantes:

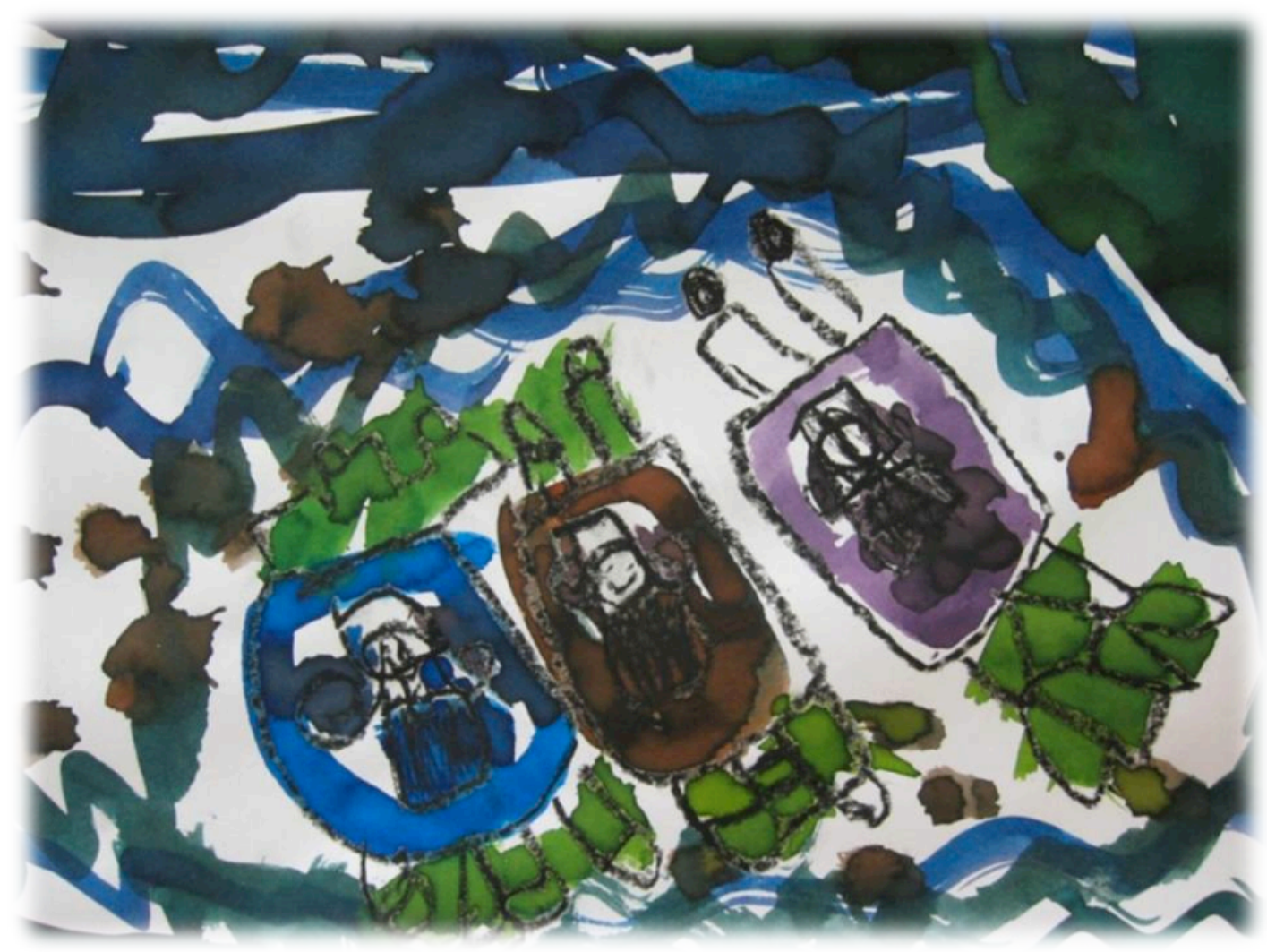

Figura 3. Mis amigas y yo ${ }^{6}$.

Esta soy yo, esta es Luiza y esta es Mariángel. Es que una vez, cuando yo era chiquitita Mariángel, yo y Luiza fuimos a un hotel y nos quedamos juntas...Son las cunas, cada una es diferente; la mía tiene un círculo aquí, un cuadrado aquí y un triángulo aquí y aquí tiene esto. (Niña de 5 años y 3 meses)

\footnotetext{
${ }^{6}$ Esta figura por ser propiedad de persona menor de edad, su uso en este artículo es autorizada por su madre. El documento con la autorización se encuentra en los archivos de la Revista Electrónica Educare.
} 
doi: http://dx.doi.org/10.15359/ree.19-1.10

URL: http://www.una.ac.cr/educare

CORREO: educare@una.cr

\section{Porque terminar es iniciar: Entre chanchos, toboganes de agua y casas de sustos}

Al mirar el camino recorrido, acepto que mi rol principal es ser mediadora del proceso de construcción. Más que esperar obras estéticamente bellas, debo asegurarme de que los niños y niñas disfruten, compartan y creen sus obras libremente, sintiendo felicidad y satisfacción por lo que hacen (Sarlé y Berdichevsky, 2010). Mi quehacer docente tiene un sentido y una razón de ser: comprenderme a mí misma desde la mirada del otro y esto me lleva a remirarme y a reflexionar acerca de todo aquello que hago en mi contexto educativo.

Concluyo mencionando que la práctica es más que la convivencia diaria con los niños y niñas; es construir y vivir una historia plétora de pensamientos, emociones, esperanzas y sueños. Solo si se vive, se aprende; nos transformamos, en especial si compartimos con otros. Ese es el instante en que se vuelve maravillosa la labor docente y surge "la esperanza de que profesor y alumnos podemos juntos, aprender, enseñar, inquietarnos, producir y juntos igualmente resistir a los obstáculos que se oponen a nuestra alegría" (Freire, 2006, p. 70). Aprendemos que podemos ser mejores; que el cambio es difícil, pero no imposible, y que somos creadores de nuestro hacer y vivir.

Ser verdaderos educadores es estar dispuestos a experimentar que nuestro interés es aprender, porque nada hacemos con comprender una técnica que nos da dominio y conocimientos, esto no necesariamente nos vuelve verdaderos creadores; mientras que si hay pasión en cada actividad realizada y en compartir lo que sabemos en una mutua convivencia, encontramos dónde está realmente el medio para expresarnos (Krishnamurti, 1972).

En los niños y niñas está la sabiduría que buscamos con ansias, en su libertad y autonomía está nuestro cambio, aprender y conocerles, pero desde una mirada a la que nunca antes le habíamos dedicado tanto interés. En sus trazos y dibujos podemos encontrar lo que nos hace falta y que hemos dejado atrás; desde ahí redescubrimos la capacidad de escuchar verdaderamente, desde el corazón, lo que ellos están ansiosos por contarnos; desde esa mirada nueva podemos maravillarnos de los detalles pequeños como en nuestra niñez; donde aprendemos que enseñar es no dar el mundo por supuesto. 
Revista EleCtrónica EdUCARE (EdUCARE ELECTRONIC JOURNAL) EISSN: 1409-4258 VOL. 19(1) ENERO-ABRIL, 2015: 167-182

doi: http://dx.doi.org/10.15359/ree.19-1.10

URL: http://www.una.ac.cr/educare

CORREO: educare@una.cr

\section{Referencias}

Acaso, M. (2009). La educación artística no son manualidades. Nuevas prácticas en la enseñanza de las artes y la cultura visual. Madrid: Los libros de la catarata.

Avery, C. (1991). Aprender cómo se investiga. Investigar cómo se aprende. En M. Olson (Comp.), La investigación-acción entra al aula (pp. 43-55). Buenos Aires: Aique Didáctica.

De Saint-Exupéry, A. (2010). El principito (3ª ed.). Bogotá: Edigrama.

Dobles, C., Zúñiga, M. y García, J. (2010). Investigación en educación: Procesos, interacciones y construcciones. San José, Costa Rica: UNED.

Freire, P. (2006). Pedagogía de la autonomía: Saberes necesarios para la práctica educativa. México: Siglo XXI.

Hoyuelos, A. (2004). La ética en el pensamiento y obra pedagógica de Loris Malaguzzi. Barcelona: Octaedro.

Krishnamurti, J. (1972). La educación y el significado de la vida. México: Editorial Orión. Recuperado de http://issuu.com/jkonline/docs/la educaci $n$ y el significado de la vida?e $=2298756 / 5178930$

Marín, R. (2003a). Aprender a dibujar para aprender a vivir. Conceptos, definiciones, teorías y perspectivas contemporáneas e la enseñanza y del aprendizaje de las artes y culturas visuales en la educación. En R. Marín (Coord.), Didáctica de la educación artística para primaria (pp. 3-52). Madrid: Pearson Educación.

Marín, R. (2003b). El dibujo infantil: imágenes, relatos y descubrimientos simbólicos. En R. Marín (Coord.), Didáctica de la educación artística para primaria (pp. 53-106). Madrid: Pearson Educación.

Mata, A. (2008). La investigación-acción para la formación continua de educadoras y educadores. San José, Costa Rica: INIE.

Molina-Jiménez, A. (2013). Expresión, comunicación y representación de vivencias en las creaciones artísticas de niñas y niños (Tésis de maestría inédita) Universidad Nacional, Heredia, Costa Rica.

Morin, E. (1999). Los siete saberes necesarios para la educación del futuro. París: UNESCO.

Palacios, J., Cubero, R., Luque, A. y Mora-Merchán, J. (2009). Desarrollo físico y psicomotor después de los 2 años. En J. Palacios, Á. Marchesi y C. Coll (Comps.), Desarrollo psicológico yeducación, Vol. 1. Piscología evolutiva (2a ed., pp. 179-200), Madrid: Alianza Editorial. 
REVISTA ELECTRÓNICA EDUCARE (EDUCARE ELECTRONIC JOURNAL) EISSN: 1409-4258 VOL. 19(1) ENERO-ABRIL, 2015: 167-182

doi: http://dx.doi.org/10.15359/ree.19-1.10

URL: http://www.una.ac.cr/educare

CORREO: educare@una.cr

Sarlé, P. y Berdichevsky, P. (2010). Juego y arte en la educación infantil. En V. Peralta y L. Hernández, Antología de experiencias de la educación inicial iberoamericana (pp. 52-56). Madrid: OEI. Recuperado de https://docs.google.com/file/d/0B4kcufl5ydzZUIBWamwxROVob2c/edit?pli=1

Vecchi, V. (2013). Arte y creatividad en Reggio Emilia. El papel de los talleres y sus posibilidades en educación infantil. Madrid: Ediciones Morata.

\section{(C) Cómo citar este artículo en APA:}

Molina-Jiménez, A. (enero-abril, 2015). El dibujo infantil: Trazos, colores e historias que nos hacen reflexionar y aprender. Revista Electrónica Educare, 19(1), 167-182. doi: http://dx.doi.org/10.15359/ree.19-1.10

Nota: Para citar este artículo en otros sistemas puede consultar el hipervínculo "Como citar el artículo" en la barra derecha de nuestro sitio web:

http://www.revistas.una.ac.cr/index.php/EDUCARE/index 